Elsevier Science Publishers B.V., Amsterdam - Printed in The Netherlands

\title{
FLOWERING-PATTERN AND YIELD COMPONENTS AT INFLORE- SCENCE NODES OF SNAP BEAN AS AFFECTED BY IRRIGATION AND PLANT DENSITY
}

\author{
CRAIGHTON S. MAUK ${ }^{1}$, PATRICK J. BREEN and HARRY J. MACK \\ Department of Horticulture, Oregon State University, Corvallis, OR 97331 (U.S.A.) \\ ${ }^{1}$ Botany Department, University of Michigan, Ann Arbor, MI 48109 (U.S.A.) \\ Oregon Agriculture Experiment Station Technical Paper No. 6760
}

(Accepted for putlication 6 October 1983)

\begin{abstract}
ABSTR.ACT
Mauk, C.S., Breen, P.J. and Mack, H.J., 1984. Flowering-pattern and yield components at inflorescence nodes of snap bean as affected by irrigation and plant density. Scientia Hortic, , 23: 9-19.
\end{abstract}

This paper reports the results of a $2 \times 2$ factorial experiment on bush snap beans 'Oregon 1604'. The treatments were 2 contrasted irrigation regimes and 2 contrasted plant densities, and were applied in 1978 and repeated in 1979. Data were collected on the number of flowers and pods, and pod size, at each node of the terminal inflorescence (6-T) of the main stem, and at each node of the oldest inflorescence (2-A) at Node 2. High and low plant densities were 45 and 18 plants $\mathrm{m}^{-2}$ in 1978 and 54 and 33 plants $\mathrm{m}^{-2}$ in 1979 . High temperatures, frequently above $32^{\circ} \mathrm{C}$, prevailed during bloom and pod development in 1978, but for the most part occurred only during the week prior to bloom in 1979. Inflorescences 6 -T and 2-A usually formed 4 and $3 \mathrm{RN}$ 's, respectively, in 1978 and 3 and 2 RN's in 1979. The flowers at the proximal nodes of each inflorescence all opened within a few days of one another (duration of flowering at proximal nodes between 3 and 5 days); the flowering-periods of adjacent nodes overlapped, and the flowering period increased acropetally within the inflorescence (duration of flowering at distal nodes between 7 and 13 days). In general, number of flowers, pods formed, pods harvested and percent set decreased acropetally within each inflorescence. The rate of acropetal decline was lessened by high irrigation or low plant density. In both years, high irrigation increased the percent set of all RN's of the 2-A inflorescences, but few other consistent effects between years were observed. The 2 most proximal RN's together produced $93 \%$ or more of the yield of each inflorescence. High irrigation significantly increased the total number of pods harvested from these RN's of inflorescences 6-T and 2-A, and low density had a similar effect on 2-A.

Keywo:ds: first-bloom; inflorescence; Phaseolus vulgaris L.; raceme node; snap bean.

\section{ABBREVIATIONS}

$\mathrm{RN}=$ raceme node; $6-\mathrm{T}=$ terminal (node 6 ) inflorescence; $2-\mathrm{A}=$ main, lateral inflorescence at mainstem node 2 . 


\section{INTRODUCTION}

High plant densities (Stang et al., 1979) and frequent irrigation (Gabelman and Williams, 1960) can greatly improve the yield of snap beans. Irrigation at bloom enhances yield by reducing flower and pod abscission (Dubetz and Mahalle, 1969). As plant density is increased, reproductive potential and pod yield of individual plants decline; the response varying within the canopy (Tanaka and Fujita, 1979) and being cultivar dependent (Stang et al., 1979). The effect of inter-plant competition and availability of soil moisture on flowering and pod development at different depths within a bean canopy are poorly understood. Information is needed on development and persistence of flowers and pods borne on individual inflorescences in order to evaluate and interpret yield effects of genotype, weather and crop management practices.

An earlier study (Mauk et al., 1983) evaluated the influence of irrigation and plant density on yield components at the terminal and a lower mainstem node of a bush snap bean cultivar. The terminal node was relatively insensitive to variation in plant density, whereas high density reduced branching and number of flowers/pods at the lower node. More frequent irrigation and greater seasonal amounts applied increased yield components at both nodes. The present study examines in detail the flowering-patterns and yield components at each raceme node within separate inflorescences arising from these mainstem nodes.

\section{MATERIALS AND METHODS}

The experimental methodology used in this study is the same as described earlier (Mauk et al., 1983). Irrigation $X$ plant density field experiments were performed with the determinate cultivar 'Oregon 1604' during the 1978 and 1979 seasons on a Chehalis clay-loam soil. A split-plot design was used in which level of irrigation (high or low) was the main plot and plant density (high or low) the sub-plot. Irrigation was applied by overhead sprinklers when soil water potential, determined from gypsum blocks at $0.3 \mathrm{~m}$ soil depth, decreased to $-0.25 \mathrm{MPa}$ (low) or $-0.06 \mathrm{MPa}$ (high). Rainfall between bloom and harvest was negligible.

Desired plant densities were obtained by machine seeding at a 0.15 $\times 0.15 \mathrm{~m}$ spacing (high) or in rows separated by $0.91 \mathrm{~m}$ with $0.05 \mathrm{~m}$ withinrow spacing (low). This resulted in plant stands of 45 versus 18 plants $\mathrm{m}^{-2}$ in 1978 and 54 versus 33 plants $\mathrm{m}^{-2}$ in 1979. First bloom, which occurred on 20 July 1978 and 23 July 1979, was defined as the day on which the majority of flowers in the axil of the terminal trifoliate (Node 6, numbering acropetally from the primary leaf node) reached anthesis. These flowers were considered an integral component of the terminal mainstem inflorescence, although they are morphologically distinct from the remainder of the raceme (Ojehomon and Morgan, 1969). Although both flowers 
at a RN frequently opened on the same day, occasionally their antheses were separated by a day.

A week prior to first bloom, 4 representative plants from each irrigationdensity sub-plot were selected and marked, thus 16 plants were monitored per irrigation-density treatment combination, totalling 64 for the experiment. The single terminal inflorescence at Node 6 (denoted 6-T), and the earliest formed branch inflorescence at Node 2 (2-A) were tagged. Although as mariy as 4 inflorescences emerged at Node 2, only 2-A was used, since it was the only inflorescence consistently present at both high and low plant densities which possessed a multiple number of RN's for comparison and stiatistical analyses. This inflorescence carried 67 and $93 \%$ of the pod yield from Node 2 in 1978 and 1979, respectively.

Every other day, from first bloom until harvest, presence or absence and the stage of development of all flowers and pods formed at each individual $\mathrm{RN}$ of both tagged inflorescences were recorded. Floral buds reaching the white-bud stage were considered as flowers. When the enlarging ovary protruded 6-8 $\mathrm{mm}$ beyond the calyx, usually 2 days after anthesis, it was regarded as an immature pod (pod formed). Recorded patterns of reproductive development from 2 days before to 2 days after anthesis were used to estimate specific dates of anthesis of flowers which failed to open on an observation day. A seasonal log of flowering was constructed for each $\mathrm{RN}$ of both inflorescences.

Plants were harvested at commercial snap bean maturity, designated as the time when approximately $50 \%$ of the pods had reached sieve size Nos. 1-4 (marketable size of fresh weight 2-11 g), 19 days after first bloom in both years. Pods were collected from each RN and weighed. Data were subjected to analysis of variance on a $R N$ per inflorescence basis to determine the significance of effects of irrigation and plant density on number of flowers produced, number of pods formed and harvested, and percent set (ratio of number of pods harvested to number of flowers formed $\times 100$ ). Due to the lack of significant treatment interaction, data for each year were pooled across irrigation-plant density treatments to evaluate the effect of $\mathrm{RN}$ position within each inflorescence on yield components.

\section{RESULiTS}

Maximum daily temperatures in 1978 were extremely high, exceeding $32^{\circ} \mathrm{C}$ on 16 days from 1 day prior to bloom until harvest (Mauk, 1982). Lower temperatures prevailed in 1979 , but there were 2 warm periods at 2-7 days before, and 8-9 days after first bloom when temperatures rose above $32^{\circ} \mathrm{C}$. Minimum daily temperatures in both years were similar (8-$14^{\circ} \mathrm{C}$ ), with the exception of the week prior to harvest in 1978 when they ranged from 14 to $17^{\circ} \mathrm{C}$.

In 1978, inflorescences $6-\mathrm{T}$ and 2 -A generally had 4 and $3 \mathrm{RN}$ 's, respec- 
tively. Occasionally, a fifth RN was formed on 6-T, but because of low frequency of formation and a lack of contribution to yield, it was not included in the analyses. Each inflorescence averaged about $1 \mathrm{RN}$ less in 1979 than in the previous year. Irrigation and plant density in most cases failed to influence the number of RN's. However, in 1979, the numbers of RN's per 2-A inflorescence were 2.81 and $2.16(P<0.001)$ at low and high density, respectively.

The flowering sequence within a bean inflorescence is acropetal, and in 1978 the majority of flowers at RN-2 and RN-3 of the 6-T inflorescence reached anthesis 1 and 2 days after those at $\mathrm{RN}-1$, respectively (Fig. 1A). The peak of flowering at RN-4, however, occurred much later, 5 days after that of RN-1. In addition, flowering-duration (days over which anthesis occurred) for RN-4 was 13 days compared to only $4-6$ days for RN's 1-3. The small peaks in flowering late in the season (9-16 days from first bloom) for RN-1 and RN-2 were due to the greater appearance at these RN's of a third flower, which failed to develop into a pod. A sequential floweringpattern was also observed in the 2-A inflorescence (Fig. 1B). However, the flowering-period at each $\mathrm{RN}$ of 2-A averaged 1-3 days longer than corresponding RN's of the 6-T inflorescence.

Flowering at RN-1 and RN-2 of the 6-T inflorescence in 1979 was similar to the patterns observed in 1978, except that the peak at RN-3 was reached 3 days after that of RN-2 (Fig. 2A). Flowering at RN's of the 2-A inflorescence preceded that of corresponding 6-T RN's by 1 day, but the floweringperiod was again longer (Fig. 2B). Although the last $\mathrm{RN}$ formed in each inflorescence in 1979 exhibited a more condensed flowering-period than those in 1978, once again its flowering was of longer duration and more irregular than that of more proximal RN's. For both inflorescences in

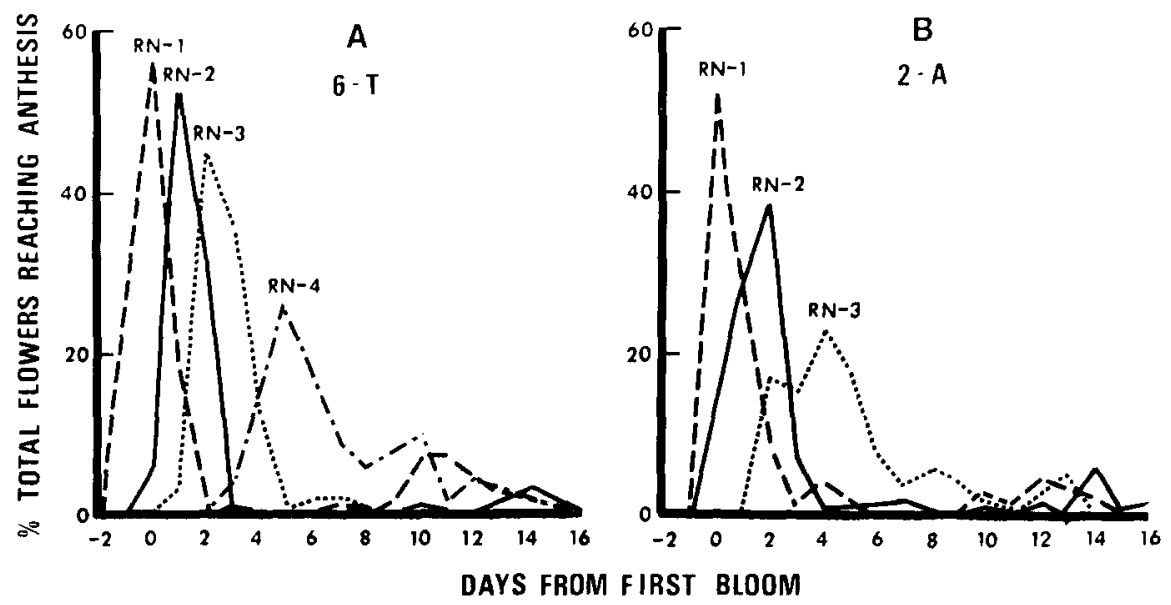

Fig. 1. Percent of total flowers that reached anthesis at each raceme node (RN) position (numbered acropetally) in inflorescences arising from the sixth mainstem node, 6-T (A), and the main inflorescence, $2-A$, at the second node $(B)$ for the 1978 season. 


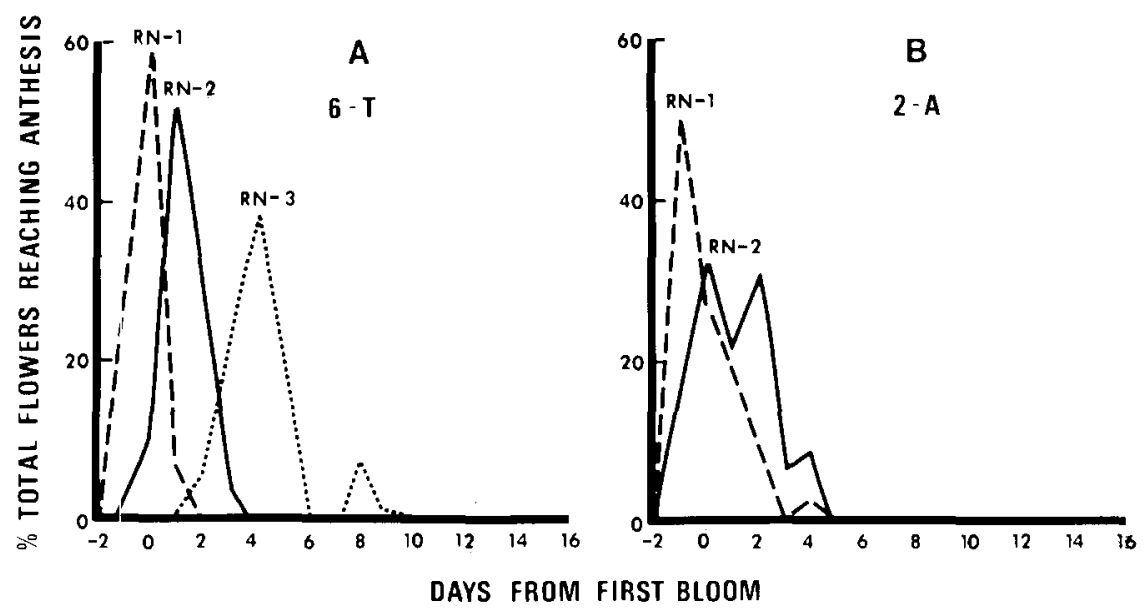

Fig. 2. Percent of total flowers that reached anthesis at each raceme node (RN) position (numbered acropetally) in inflorescences arising from the sixth mainstem node, 6-T (A), and the main inflorescence, 2-A, at the second node (B) for the 1979 season.

each year, neither irrigation nor plant density affected the flowering-pattern at a particular RN (Mauk, 1982).

Yield components generally decreased acropetally within each inflorescence for 1978 (Table I). For example, normalizing number of flowers formed at each $\mathrm{RN}$ of $6-\mathrm{T}$ to that of $\mathrm{RN}-1$ gives values of: $\mathrm{RN}-1,1.00$; $\mathrm{RN}-2,0.82 ; \mathrm{RN}-3,0.73 ; \mathrm{RN}-4,0.58$. Mean set for the 2 most proximal RN's of $6-T$ was $40 \%$ compared to only $18 \%$ for distal RN's. Similarly, the number of pods harvested from the lower half of the terminal inflorescence was 3-fold larger.

There were no significant plant density effects on yield components of individual RN's of 6-T in 1978, although irrigation effects were observed (Table I). Low irrigation increased flowering at $\mathrm{RN}-1$ due to more frequent emergence of a third flower late in the season. High irrigation significantly increased number of pods formed at RN-3 as well as percent set and final number of harvested pods at both RN-2 and RN-3.

The rate of acropetal decline within yield components in the 2-A inflorescence, which had 3 RN's, was much less than that in 6-T (Table I). For example, comparison of mean values of the 2 most proximal RN's with those of RN-3 shows that number of flowers, pods formed and pods harvested decreased by 18,14 and $38 \%$, respectively. High irrigation significantly improved percent set of all RN's of inflorescence 2-A (Table I). High irrigation also increased number of pods harvested from $\mathrm{RN}-2$ by over 2 -fold. Yield components in the 2-A inflorescence were nearly always greater at low compared to high density, but differences were often not significant.

In 1979, each inflorescence exhibited approximately 1 less $R N$. The 6-T irflorescence only possessed $3 \mathrm{RN}$ 's and the third RN produced sig- 


\section{TABLE I}

Influence of irrigation and plant density on yield components of 'Oregon 1604' snap beans at individual raceme nodes in inflorescences arising from the sixth mainstem node (6-T) and the main inflorescence (2-A) at the second node for the 1978 season

\begin{tabular}{|c|c|c|c|c|c|c|}
\hline \multirow[t]{3}{*}{ Inflorescence } & \multirow{3}{*}{$\begin{array}{l}\text { Raceme } \\
\text { node }\end{array}$} & \multicolumn{4}{|c|}{ Treatment } & \multirow{3}{*}{$\begin{array}{l}\text { Overall } \\
\text { mean }\end{array}$} \\
\hline & & \multicolumn{2}{|c|}{ Irrigation } & \multicolumn{2}{|c|}{ Density } & \\
\hline & & High & Low & Low & High & \\
\hline \multicolumn{7}{|c|}{ Number of flowers } \\
\hline \multirow[t]{4}{*}{$6-\mathrm{T}$} & 1 & $2.53^{*}$ & 2.81 & 2.59 & 2.75 & 2.67 \\
\hline & 2 & 2.19 & 2.19 & 2.19 & 2.19 & 2.19 \\
\hline & 3 & 1.88 & 2.00 & 1.94 & 1.94 & 1.94 \\
\hline & 4 & 1.81 & 1.31 & 1.47 & 1.66 & 1.56 \\
\hline \multirow[t]{3}{*}{$2-\mathrm{A}$} & 1 & 2.28 & 2.43 & 2.47 & 2.25 & 2.36 \\
\hline & 2 & 2.09 & 2.34 & $2.34^{*}$ & 2.09 & 2.22 \\
\hline & 3 & 1.81 & 1.97 & 1.97 & 1.81 & 1.89 \\
\hline
\end{tabular}

Number of pods formed

6-T

$\begin{array}{lllll}1.81 & 1.81 & 1.88 & 1.75 & 1.81 \\ 1.06 & 0.84 & 0.97 & 0.94 & 0.95 \\ 1.31 * * * & 0.25 & 0.72 & 0.84 & 0.78 \\ 1.03 & 0.78 & 1.00 & 0.81 & 0.91 \\ 1.63 & 1.38 & 1.69 & 1.31 & 1.50 \\ 1.78 * * & 1.06 & 1.59 & 1.25 & 1.42 \\ 1.44 & 1.06 & 1.41 & 1.09 & 1.25\end{array}$

Percent set

$\begin{array}{lllrrrr}6-\mathrm{T} & \mathbf{1} & \mathbf{5 8 . 5} & 48.2 & 57.2 & 49.5 & 53.4 \\ & 2 & 35.1^{*} & \mathbf{1 4 . 5} & 23.2 & 26.3 & 24.8 \\ & 3 & 22.9^{* *} & 4.7 & \mathbf{1 7 . 7} & 9.9 & 13.8 \\ & 4 & 22.9 & 19.4 & 26.7 & 15.5 & 21.2 \\ 2-\mathrm{A} & \mathbf{1} & 60.1^{*} & 38.7 & 54.7 & 44.1 & 49.4 \\ & 2 & 59.7^{*} & 23.3 & 50.6 & 32.4 & 41.5 \\ & 3 & 43.3^{*} & 23.9 & 37.3 & 29.9 & 33.6\end{array}$

Number of harvested pods

$\begin{array}{lllllll}6-\mathrm{T} & 1 & 1.47 & 1.34 & 1.47 & 1.34 & 1.41 \\ & 2 & 0.75^{* *} & 0.31 & 0.50 & 0.56 & 0.53 \\ & 3 & 0.44 & 0.09 & 0.34 & 0.19 & 0.27 \\ & 4 & 0.28 & 0.41 & 0.28 & 0.41 & 0.34 \\ 2-\mathrm{A} & 1 & 1.38 & 0.94 & 1.34^{*} & 0.97 & 1.16 \\ & 2 & 1.25 * & 0.53 & 1.13 & 0.66 & 0.89 \\ & 3 & 0.78 & 0.47 & 0.72 & 0.53 & 0.63\end{array}$

$* P<0.05, * * P<0.01$ and $* * * P<0.001$ for means within irrigation or plant density at the same inflorescence raceme node. 
TABLE II

Influence of irrigation and plant density on yield components of 'Oregon 1604' at individual raceme nodes in inflorescences arising from the sixth mainstem node (6-T) and main inflorescence (2-A) at the second node for the 1979 season

\begin{tabular}{|c|c|c|c|c|c|c|}
\hline \multirow[t]{3}{*}{ Inflorescence } & \multirow{3}{*}{$\begin{array}{l}\text { Raceme } \\
\text { node }\end{array}$} & \multicolumn{4}{|l|}{ Treatment } & \multirow{3}{*}{$\begin{array}{l}\text { Overall } \\
\text { mean }\end{array}$} \\
\hline & & \multicolumn{2}{|l|}{ Irrigation } & \multicolumn{2}{|l|}{ Density } & \\
\hline & & High & Low & Low & High & \\
\hline \multicolumn{7}{|c|}{ Number of flowers } \\
\hline \multirow[t]{3}{*}{$6-\mathrm{T}$} & 1 & 2.88 & 2.97 & 2.97 & 2.88 & 2.92 \\
\hline & 2 & 2.69 & 2.59 & $2.88 * * *$ & 2.40 & 2.64 \\
\hline & 3 & 1.81 & 1.38 & 1.56 & 1.63 & 1.59 \\
\hline \multirow[t]{2}{*}{$2-\mathrm{A}$} & 1 & 2.09 & 2.34 & .2 .22 & 2.22 & 2.22 \\
\hline & 2 & 2.00 & 1.88 & $2.13^{*}$ & 1.75 & 1.94 \\
\hline \multicolumn{7}{|c|}{ Number of pods formed } \\
\hline \multirow{3}{*}{$6-\mathrm{T}$} & 1 & 2.25 & 2.16 & $2.31 *$ & 2.10 & 2.20 \\
\hline & 2 & $2.19 * * *$ & 1.81 & $2.13^{*}$ & 1.88 & 2.00 \\
\hline & 3 & 1.18 & 1.06 & 1.09 & 1.16 & 1.13 \\
\hline \multirow[t]{2}{*}{$2-\mathrm{A}$} & 1 & 1.81 & 1.78 & 2.00 & 1.63 & 1.81 \\
\hline & 2 & 1.69 & 1.38 & $1.78^{*}$ & 1.28 & 1.53 \\
\hline \multicolumn{7}{|l|}{ Percent set } \\
\hline \multirow[t]{3}{*}{$6-\mathrm{T}$} & 1 & 63.4 & 64.2 & 63.2 & 64.5 & 63.8 \\
\hline & 2 & 59.0 & 52.0 & 54.3 & 56.9 & 55.6 \\
\hline & 3 & 31.7 & 33.3 & 38.8 & 27.2 & 32.5 \\
\hline \multirow[t]{2}{*}{$2-\mathrm{A}$} & 1 & $77.6 *$ & 66.9 & $82.6 *$ & 61.9 & 72.2 \\
\hline & 2 & 76.3 & 39.3 & 60.8 & 54.9 & 57.8 \\
\hline \multicolumn{7}{|c|}{ Numbe:t of harvested pods } \\
\hline \multirow[t]{3}{*}{$6-\mathrm{T}$} & 1 & 1.91 & 1.81 & 1.88 & 1.84 & 1.86 \\
\hline & 2 & 1.59 & 1.47 & 1.56 & 1.38 & 1.47 \\
\hline & 3 & 0.44 & 0.56 & 0.53 & 0.47 & 0.50 \\
\hline \multirow[t]{2}{*}{$2 \cdot \mathrm{A}$} & 1 & 1.59 & 1.53 & $1.78 * *$ & 1.34 & 1.56 \\
\hline & 2 & $1.56^{*}$ & 0.72 & 1.31 & 0.97 & 1.14 \\
\hline
\end{tabular}

$* P<0.05, * * P<0.01$ and $* * * P<0.001$ for means within irrigation or plant-density treatments at the same inflorescence raceme node.

nificaritly less flowers and pods than either of the 2 more proximal RN's (Table II). A similar number of flowers and pods was produced by RN-1 and $\mathrm{RN}-2$ of $6-\mathrm{T}$; however, the yield of $\mathrm{RN}-1$ was twice that of RN-2 due to a greater pod size (see Table III). Only 2 RN's appeared in the 2-A inflorescence in 1979, and differences in yield components between them were usually slight.

Irrigation had less of an effect on yield components of 6-T in 1979. However, low density significantly increased number of pods formed at 
RN-1 and RN-2 (Table II). Irrigation-density effects on yield components for RN's of 2-A in 1979 were similar to those in 1978, with the exception that low density also increased number of pods formed at $\mathrm{RN}-2$.

In general, irrigation-density treatment did not significantly affect average pod fresh and dry weight at any individual RN; nor was any treatment effect noted on the distribution of pod yield within the 6-T and 2-A inflorescence (Mauk, 1982). Pooling treatment means, however, showed a pronounced acropetal decline in pod size and distribution of yield on a RN per inflorescence basis in both years (Table III). In 1978, for example, $82 \%$ of the yield at $6-\mathrm{T}$ was carried at $\mathrm{RN}-1$, and the combined contribution of RN's 3 and 4 was less than $3 \%$. The following year, 6-T produced an average of 1 less $\mathrm{RN}$, which resulted in RN-2 carrying a larger percentage of yield at 6-T. Pod fresh weight also declined acropetally and was much greater at the proximal $(\mathrm{RN}-1,2)$ compared to the distal RN's (RN's 3,4).

RN's at the 2-A inflorescence showed an analogous acropetal decline in pod fresh weight and contribution to total inflorescence yield (Table III), yet the discrepancy between $\mathrm{RN}-1$ and $\mathrm{RN}-2$ was not as great as for those RN's of 6-T.

\section{TABLE III}

Pod yield, distribution and mean pod weight at each raceme node within inflorescences arising from the terminal mainstem node $(6-\mathrm{T})$ or the second mainstem node (2-A) in the 1978 and 1979 seasons

\begin{tabular}{llllll}
\hline Year & Inflorescence & $\begin{array}{l}\text { Raceme } \\
\text { node }\end{array}$ & $\begin{array}{l}\text { Fresh weight } \\
\text { pod yield } \\
(\mathrm{g} \pm \text { S.E. })\end{array}$ & $\begin{array}{l}\text { Yield } \\
\text { distribution } \\
(\% \pm \text { S.E. })\end{array}$ & $\begin{array}{l}\text { Mean fresh } \\
\text { weight/pod } \\
(\mathrm{g} \pm \mathrm{S} . \mathrm{E} .)\end{array}$ \\
\hline 1978 & $6-\mathrm{T}$ & 1 & $9.3 \pm 0.5$ & $82.3 \pm 1.6$ & $6.62 \pm 0.17$ \\
& & 2 & $1.7 \pm 0.3$ & $15.0 \pm 1.4$ & $3.12 \pm 0.16$ \\
& 3 & $0.1 \pm 0.1$ & $0.8 \pm 0.4$ & $0.38 \pm 0.09$ \\
& & 4 & $0.2 \pm 0.1$ & $1.8 \pm 0.5$ & $0.66 \pm 0.08$ \\
& $2-\mathrm{A}$ & 1 & $9.3 \pm 1.1$ & $62.0 \pm 1.4$ & $8.05 \pm 0.19$ \\
& & 2 & $4.8 \pm 1.1$ & $31.0 \pm 2.5$ & $5.28 \pm 0.43$ \\
& & 3 & $1.0 \pm 0.3$ & $6.7 \pm 1.0$ & $1.61 \pm 0.29$ \\
1979 & $6-\mathrm{T}$ & 1 & $11.3 \pm 0.7$ & $64.9 \pm 0.2$ & $6.09 \pm 0.25$ \\
& & 2 & $5.7 \pm 0.3$ & $32.2 \pm 0.5$ & $3.82 \pm 0.27$ \\
& & 3 & $0.5 \pm 0.0$ & $2.9 \pm 0.3$ & $1.08 \pm 0.37$ \\
& $2-\mathrm{A}$ & 1 & $8.8 \pm 1.2$ & $64.7 \pm 3.9$ & $5.54 \pm 0.43$ \\
& & 2 & $4.7 \pm 0.9$ & $35.3 \pm 4.1$ & $4.16 \pm 0.07$ \\
\hline
\end{tabular}

\section{DISCUSSION}

One assessment of reproductive potential in snap bean is the number of RN's per inflorescence. Inflorescences of 'Oregon 1604' had as few 
as 2 and as many as 5 RN's. The year-effect on RN numbers and the very different seasonal temperature patterns in the 2 years suggest that the number of RN's produced per inflorescence is strongly influenced by timing and magnitude of high temperatures. Since temperatures in excess of $30^{\circ} \mathrm{C}$ are quite detrimental to flower bud differentiation in beans (Watanabe, 1954; Inoue, 1955), it can be expected that they would affect subsequent expression of the number of RN's as assesed in this study by the presence of flower buds $2-5$ days before anthesis. Temperatures exceeding $32^{\circ} \mathrm{C}$ in the week prior to first bloom were probably the major contributing factor to the decreased number of RN's per inflorescence in 1979.

The $30 \%$ increase in number of RN's of the 2-A inflorescence under low plant density in 1979 demonstrates that plant density can alter reproductive potential at lower nodes through both the number (Mauk, 1982) and size of inflorescences. Since most of the yield on an inflorescence was carried by RN's 1 and 2 (Table III), additional RN's had a limited effect on yield. The intrinsic pattern of flower production at each RN, which is largely a positional effect, also influenced yield components. In both inflorescences, flowering at proximal RN's was of short duration, whereas at distal RN's it was erratic and considerably longer, often lasting a week or more (Figs. 1 and 2). Extended and delayed flowering at distal RN's is not compatible with once-over machine harvesting, since many of the pods at these RN's are immature when a majority are at harvest maturity. Irrigation treatment or plant density exhibited little influence on the flowering-pattern of a $\mathrm{RN}$, which is probably more reflective of a particular genotype than a response to cultural practices.

Irrigation and plant density treatments, however, did influence the final number of flowers formed. Low irrigation, for example, increased the number of flowers at RN-1 of the 6-T inflorescence (Table I). Even though these additional flowers did not produce harvestable pods (Mauk, 1982), it demonstrates that moderate water stress at certain instances in reproductive development can increase flower production. The tendency of low plant density to increase flower production of RN's of the 2-A inflorescence (Tables I and II) coincides with its enhancement of branching and inflorescence formation and development lower in the canopy (Mauk et al., 1983).

In addition to the number of flowers reaching anthesis, other yield components (i.e., percent set and number of pods formed and harvested) displayed a significant acropetal decline within each inflorescence (Tables I and J.I). Within a bean inflorescence there exists asynchrony in pod growth among RN's in which the lower-most pods exhibit maximum growth rates when those at higher RN's are just being formed (Walbot et al., 1972). Because of this developmental pattern, flowers and pods at more distal RN's are likely to be at a disadvantage in competing for water, assimilate or other nutrients. The growth of distal flowers may even be retarded prior to opening (Huff and Dybing, 1980). However, reduced growth and 
greater loss of organs at distal RN positions is a function of flowers and pods at lower RN's rather than positional effect per se (Tamas et al., 1979). Removing older, proximal pods from a bean inflorescence increases growth and reduces abscission of more distal organs (Gage, 1978) as well as diminishing their abscisic acid content (Tamas et al., 1979).

This disadvantage conferred to later-to-form flowers and pods within the inflorescence can be lessened through cultural practices. High irrigation and low plant density sometimes reduced the effect of RN location by increasing percent set and number of pods formed and harvested at more distal RN's (Tables I and II). Although the irrigation effect was evident in both years, it was more marked in the more stressful year of 1978 where high temperatures prevailed from first bloom until harvest (Mauk, 1982).

Overall distribution of yield (total pod fresh weight and weight per pod formed within an inflorescence) was also strongly governed by RN position, and the pods at the first $\mathrm{RN}$ account for the largest proportion (Table III). In fact, over $93 \%$ of the total yield was attributed to the first 2 RN's. Pods at these RN's developed first and had 14-16 days to grow prior to harvest, whereas those at RN-3 had only 10- 12 days. In addition, growth of pods at distal positions may have been slowed as a result of nutrient competition and/or hormonal effects (Ojehomon, 1972; Van Steveninck, 1957). Such effects could be expected to intensify under stressful environments (Kambal, 1969). The supply of photosynthate would probably be reduced by low soil moisture availability and high plant densities.

It would appear desirable to reduce asynchrony of growth patterns of flowers and pods at progressively more distal RN's within major yieldproducing inflorescences of snap beans. Such a result would increase the proportion of pods of a crop which simultaneously reach marketable size, thereby improving yield obtained in a once-over machine harvest.

\section{ACKNOWLEDGEMENTS}

The authors wish to express appreciation to the Agricultural Research Foundation for financial support and to Suzie Maresh for statistical consulation and analyses.

\section{REFERENCES}

Dubetz, S. and Mahalle, P.S., 1969. Effect of soil water stress on bush beans Phaseolus vulgaris L. at three stages of growth. J. Am. Soc. Hortic. Sci., 92: 479-481.

Gabelman, W.H. and Williams, D.D.F., 1960. Developmental studies with irrigated snap beans. Wis. Agric. Exp. Stn. Bull. 221, pp. 1-56.

Gage, J.F., 1978. Effect of pod removal on flower production in French bean (Phaseolus vulgaris). Queensl. J. Agric. Anim. Sci., 35: 63-68.

Huff, A. and Dybing, C.D., 1980. Factors affecting the shedding of flowers in soybean (Glycine max (L.) Merrill). J. Exp. Bot., 31: 751-762. 
Inoue, Y., 1955. Studies on the reproductive physiology of common beans (Phaseolus vulgcris L.) IV. Some relations among the flower bud differentiation, flowering, and iruiting in common beans. J. Hortic. Assoc. (Japan), 24: 56-58.

Kambal, A.E., 1969. Flower drop and fruit set in field beans, Vicia faba L. J. Agric. Sci., 72: 131-138.

Mauk, C.S., 1982. Influence of irrigation and plant population on yield parameters, flower and pod abscission, and photosynthate distribution in snap beans, Phaseolus vulgaris L. var. 'Oregon 1604'. Ph.D. Thesis, Oregon State University, Corvallis, pp. $1-149$.

Mauk, C.S., Breen, P.J. and Mack, H.J., 1983. Yield response of major pod-bearing nodes in bush snap beans to irrigation and plant population. J. Am. Soc. Hortic. Sci., 108: 935--939.

Ojehomon, O.O., 1972. Fruit abscission in cowpea, Vigna unguiculata (L.) J. Exp. Bot., 23: $751-761$.

Ojehomon, O.O. and Morgan, D.G., 1969. A quantitative study of inflorescence development in Phaseolus vulgaris. Ann. Bot., 33: 325--332.

Stang, J.R., Mack, H.J. and Rowe, K.E., 1979. Quantitative relation of bush snap bean (Phaseolus vulgaris L.) yields to plant population density. J. Am. Soc. Hortic. Sci., $104: 873-875$.

Tamas, I.A., Wallace, D.H., Ludford, P.M. and Ozbun, J.L., 1979. Effect of older fruits on abortion and abscisic acid concentration of younger fruits in Phaseolus vulgaris L. Plant Physiol., 64: 620-622.

Tanaka, A. and Fujita, K., 1979. Growth, photosynthesis and yield components in relation to grain yield of the field bean. J. Fac. Agric., Hokkaido Univ., 59: 145-238.

Van Steveninck, R.F.M., 1957. Factors affecting the abscission of reproductive organs in yellow lupins (Lupinus luteus L.). I. The effect of different patterns of flower removal. J. Exp. Bot., 8: 373-381.

Walbot, V., Clutter, M. and Sussex, I.M., 1972. Reproductive development and embryogeny in Phaseolus. Phytomorphology, 22: 59-68.

Watanabe, H., 1954. Studies on the unfruitfulness of the beans. I. Influence of temperature on the flower bud differentiation and blooming. J. Hortic. Assoc. (Japan), 22: $100-106$. 